\title{
The university and social responsiveness in the curriculum: a new form of scholarship?
}

Judith Favish* and Janice McMillan

University of Cape Town, South Africa

\begin{abstract}
Challenges facing the higher education sector globally include questions over what counts as knowledge and what are valid forms of both its reproduction and production. This paper addresses the question of how what counts as valid knowledge is challenged and how it changes over time. It does this via an analysis of examples of social responsiveness profiled as 'portraits of practice' in the annual social responsiveness reports produced at the University of Cape Town, South Africa, a traditionally strong research university. In this paper, we discuss and analyse key themes emerging from this work and argue that social responsiveness not only serves to enhance the core functions of teaching and research but can act to change them.
\end{abstract}

Keywords: higher education transformation; scholarship; curriculum; social responsiveness; knowledge; community; service

\section{Introduction}

Challenges facing the higher education sector globally include questions over what counts as knowledge and what are valid forms of both its reproduction and production. As part of this, many institutions are beginning to re-think their criteria for recognizing scholarship and the ways in which knowledge that is socially responsive can be central to notions of scholarship. Via a case study of social responsiveness (SR) at the University of Cape Town (UCT), South Africa, this paper addresses the question of how what counts as knowledge is slowly being challenged. By so doing, it raises the following issues linked to knowledge and the curriculum:

- The debates about the changing nature of knowledge and about the values of different kinds of knowledge.

- An assessment of the degree to which these changes are evident in curricula in higher education.

- The notion of evaluating curricula in terms of the kind of graduates they are producing.

- Implications of such issues for pedagogy in higher education.

The paper will begin with a brief outline of the South African higher education context, including the UCT context. Following this we consider some of the debates about social responsiveness and the curriculum and highlight a number of key concepts framing our analysis. The next section describes and analyses examples of social responsiveness practice taken from interviews with academic and students conducted in compiling UCT's Annual social responsiveness reports 2005-2007. Additional information was gleaned from documents, papers, websites and other relevant material provided by the interviewees. To capture the complexity and richness of these practices, it was decided to present the reports in the form of 'portraits of practice'

*Corresponding author. Email: judy.favish@uct.ac.za 
(Stanton 2000) in order to facilitate debate across the wider university community about different forms this aspect of scholarship takes. Here we identify four themes which provide the framework for our analysis. We conclude by arguing that engaging with society not only serves to enhance the core functions of teaching and research, but can actually act to change the knowledge base of the academy itself. And in a context like South Africa, a society characterized by high levels of inequality and poverty, it is critical that we begin this process from within our own higher education institutions. We also hope that the paper might have relevance for current debates internationally about higher education's role in contributing to social and economic development.

\section{Background context}

The South African Higher Education White Paper of 1997 on transformation identifies the multiple purposes of higher education $(\mathrm{HE})$, including the need for higher education to contribute to development and critical citizenship. Accordingly the National Plan for Higher Education (200I) argues that it is important for $\mathrm{HE}$ institutions to work towards:

The development and delivery of relevant curricula which contribute to providing high-level skills training which (in turn) will 'develop professional and knowledge workers with globally equivalent skills, but who are socially responsible and conscious of their role in contributing to the national development effort and social transformation' (Ministry of Education 200I, 7).

UCT produces annual research and teaching and learning reports which are submitted to the university council as a way of accounting for the annual teaching and research activities at UCT. However, neither of these reports explicitly addresses the ways in which UCT is responding to the needs and challenges in our local, regional, national, African and global contexts. UCT thus decided to produce an annual social responsiveness report which would make Cut's contributions to broader social, cultural and economic development more visible both internally and externally.

UCT conducted its first annual review of SR in 2003 and this process was refined over the next four years. Given the different understandings and forms of SR on campus, it became important to design the SR project in such a way that would enable the university to deepen its own understanding of the different forms that it took on campus. Based on this, portraits of practice have been collected each year to facilitate informed debate about the nature of SR at UCT and appropriate ways of assessing these activities in the performance review system for academics. In order to select the portraits, the following working definition of SR was used:

- Scholarly based activities (including use-inspired basic research, Stokes 1997) that have projected and defined outcomes that match or contribute to developmental objectives or policies defined by civil society, local, provincial or national government, international agencies or industry.

This definition reflected the view that SR should embody a recognition of the need for universities to 'respond' to the needs of society through the use of scholarship in ways that add value to society but in a manner that feeds back into research and teaching at the university. Two other elements of the definition are worth pointing out: it reflects the fact that most of the university's SR activities involve relationships of varying kinds with external constituencies and that SR emphasized the scholarly forms of social responsiveness work.

We move now to the next section which highlights a number of key concepts in the social responsiveness literature that have influenced our thinking and analysis. This enables us to locate our analysis within a broader conceptual framework. 


\section{Framing the analysis: key concepts}

Ernest Boyer (1996) spoke of 'a new model of excellence' where the university celebrates teaching and research while also taking pride in acknowledging and celebrating a 'scholarship of engagement'. Cox (2006) argues that the notion of a 'scholarship of engagement' is different from more traditional notions of scholarship whose 'cues for questions and choices for instruction are driven only by the development of theory within academic disciplines' (Cox 2006, I25). In the 'scholarship of engagement', in contrast, those cues 'are driven by and answers are produced through contact with persons and places outside of the academy' (ibid., 125).

This shifts the emphasis onto thinking about the nature of the producers of knowledge in society. Gibbons (2006), in reflecting on the role of higher education in society, argues that the prevailing contract with universities is based on an expectation that universities provide new knowledge and train new generations of scientists supported by government and industry. In terms of this contract research agendas are set by the universities and the results of the research are communicated mainly in academic journal. In this paradigm information 'travels in one direction with little impact on the universities, their organization or their ethos' (Gibbons 2006, 5). However, there is a growing body of international literature which has started to challenge this view of the nature of the social contract between universities and society on the grounds that knowledge is now being produced in multiple sites. Added to this is the argument that there is a growing need for socially robust knowledge which builds a deeper understanding of complex systems and problems as a result of being generated and tested in a broad range of contexts, not just in specific laboratory conditions (Gibbons 2006; Bawa 2003; Nyden 2006). Gibbons has posited the notion of the 'agora' or a 'transactional space' which comprises a:

... problem-generating and problem-solving environment... populated by academics and other 'publics' in which all partners bring something that can be exchanged or negotiated... where the success of these exchanges depends upon each participant bringing something that is considered valuable by someone else - whatever that value might be. (Gibbons 2006, 19)

Underpinning Gibbons' approach is the belief that universities should be placed in a new relationship with society in which external constituencies are active partners in the learning process, and where learning is diverse and serves a variety of purposes giving rise to a diversity of ' $k$ nowledges' (Bawa 2003).

Recognizing a diversity of knowledges is particularly important in the African context where:

... one of the pillars of the African Renaissance is the creation of indigenous knowledge and its exploitation in the solution of problems to redress the fact that mainstream knowledges have largely become synonymous with exogenous knowledges (Odora-Hoppers, 2006). By this is meant the active participation (of communities) in the creation of new knowledge, in the imbibing of existing knowledge, in its dissemination, and in its infusion into problem-solving. (Bawa 2003, 54)

Odora-Hoppers argues further that conceptualizing the notion of 'public benefit' in the South African context should embody a recognition of the weight of the apartheid system that has underpinned South Africa's past necessitating a focus on global and redistributive concerns in thinking about the kind of graduates which public higher education institutions in South Africa need to produce. She proposes that:

... to produce graduates prepared to play an important role in society, and take over responsibility for a nation's future, students must be treated as academic citizens... able to contemplate the future of society, and design and construct the desired institutional pathway to the future. (Odora-Hoppers 2006, 50)

In this regard Odora-Hoppers suggests that it is critical to reflect on how universities can support educational programmes and 'practices that are conducive to critical discourse and 
creative thinking, cultural tolerance and a common commitment to a humane, just, non-racist and non-sexist social order' (Odora-Hoppers 2006, 59).

In proposing how this challenge can be met, Swartz (2006) argues that social engagement where players from the university become involved in relationships with external constituencies is a critical vehicle for producing academic citizens provided that:

... the university does not speak at society from above (and that) it engages with societal actors as equal partners in a discursive and democratic set of social relations. In these relationships, universities bring their consideration knowledge assets to the table, which, together with the indigenous knowledge of communities, social networks and resources in society, provide building blocks for different forms of development. (Swartz 2006, 142)

One of the pedagogical practices that have developed in this context is that of service learning or community-based learning. In terms of the practice itself, Moore (2000) locates service learning as a branch of experiential education. 'What is important is that while definitions of service learning vary, they all encompass two components: student learning and student engagement in projects with a community service orientation. In understanding some of the underpinning principles guiding much service learning practice, it is important to acknowledge the work of John Dewey (1916, 1927, 1938). Drawing on Dewey's work, Giles and Eyler (1994) argue that it is important to link learning to issues such as citizenship and democracy. By not doing this, we create a 'false dichotomy between the ideas related to learning and those related to citizenship and democracy' (Robertson 1992, 337, in Giles and Eyler 1994, 78-9; emphasis in the original). Key issues to understand in Dewey's work are the relationships between reflection, inquiry and experimentalism. In particular, his emphasis on the principles of experience, inquiry and reflection as key elements to a 'theory of knowing' in service learning, help us to think about how learning takes place, what the learning is and the relation of learning to action. Others have argued that linking experience and reflection is not solely about learning but also about educating students to play an important role in civic life, enabling them to analyse the social and economic purposes of society and contribute to improving society (Lisman 1998). Another viewpoint emphasizes higher education's responsibilities in regard to fostering practices needed for citizenship through direct engagement in democratic activities, integrating multicultural themes across the curriculum, promoting democratic education on campuses and preparing students to work in ethnically diverse societies (Murphy 2000; International Consortium for Higher Education 2000).

We turn now to look at the portraits of practice. This is not an inclusive discussion of all the portraits in the reports thus far, ${ }^{2}$ rather, we have been particularly interested in surfacing social responsiveness practices related to the curriculum. As a result, we will focus the remainder of this paper on analyzing examples where teaching, learning or the curriculum were impacted on or changed by the activity. We will do this by grouping the examples according to key themes we identified. These themes in turn link to the conceptual issues discussed above, enabling us to contribute to broader debates about the role of higher education in serving society - and to view it as a new form of scholarship.

\section{Description and analysis of the 'portraits of practice'}

Reflecting on some of these theoretical constructs above, we will examine the work of academics and students showcased in the UCT SR reports. Before we begin however, we need to qualify our discussion of the examples. We realize that given the complexity of this work, the themes above cut across a number of the portraits and could thus be discussed under more than one theme. That said, except in a few instances, we have only discussed each portrait under one theme; in addition we have selected to foreground only certain aspects of 
each for this paper. Our analysis could therefore appear a bit simplistic. However, we see this process as the first step in trying to make sense of complex practices existing at the interface, in the 'agora' or 'transactional space' between the university and the wider community of which it is a part. We have also not covered all the portraits in this paper but, as noted in the beginning of the paper, have focused on those where curriculum impact is an explicit part of the practice.

In order to frame our analysis, we have devised four themes which illustrate the points above. Drawing on the themes, we illustrate how social responsiveness is providing opportunities for:

- Contextualizing the curriculum in line with a commitment to producing graduates with the knowledge and competencies to engage with challenges facing South African society.

- Challenging dominant epistemologies and practising models of knowledge generation that build on local knowledge, and university-local community collaboration.

- Mediating the interface between theory and practice.

- Transforming the curriculum to reflect new notions of professional practice.

\section{Contextualizing the curriculum in line with a commitment to producing graduates with the knowledge and competencies to engage with challenges facing South African society}

Several of the portraits describe how academics draw on their SR activities in their teaching to contextualize theoretical constructs, to introduce new courses to address gaps identified through practical experience in the field, and to provide opportunities for students to engage with real life cases. Through this students are introduced to forms of knowledge that facilitate their understanding of many of the challenges facing South African society.

The Industrial Health Research Group describes its value to UCT as follows:

Our experience, expertise and the special value that we offer to the university, lies in the socially responsive content and methodology of our Occupational Health \& Safety advice service, education and training work, and participatory research programmes. (UCT 2006, 25)

Ntsebeza of the sociology department describes himself as 'an academic and an activist' (UCT 2005, 26). He draws on his work with a wide range of non-governmental organizations in his research on land reform. His practical involvement with these social movements has enriched his teaching in various ways. He uses examples from his knowledge of the South African rural experience to explain theoretical constructs. He has also introduced new courses and new course content based on the new knowledge he has acquired through his work around land reform with social movements.

The UCT's Unilever institute of strategic marketing conducts research designed to provide marketers and marketing students with a deeper understanding of the dynamics of the South African marketplace. Their research is based on collaborative university-community partnerships with members of different communities participating in the design of the research methodology, the interpretation of the findings and the dissemination of the results. Such an approach is in line with adding chairs to the research table (Nyden 2006). The research has enabled the school of management studies to change the marketing curriculum and learning materials to enhance their relevance for the South Africa context. The school produced a book of concepts and case studies, based on a synthesis of the institute's research projects, which is going into its third edition in three-and-a-half years. As a result of integration of the research findings into the curriculum, the department feels that their graduates are 'much better equipped to handle marketing from a South African perspective rather than simply using the standard textbook approach to marketing' (UCT 2006, 55). 
Black from the economics department became involved in the formulation and implementation of a motor industry development programme working with the Department of Trade and Industry and the Motor Industry Development Council as a result of the research he had been conducting into the motor industry. According to Black, having the opportunity to put his research into practice in such a direct way has been a unique and enormously valuable experience. His direct involvement in the policy process strengthened his understanding of policy issues. He has used his work with the automotive industry to introduce new components in his teaching, for instance a master's level course on trade and industrial policy. The school of economics also introduced an honours-level course on policy analysis in which the automotive policy comprises a module (UCT 2005). Significantly Black argued that his direct involvement in the policy process enabled him to gain access to stakeholders which would normally not be possible and hence to enrich the knowledge generation process.

In a similar way economists in the school of economics involved in a project with the National Treasury researching macro-economic policy have used the research findings to enrich the curriculum through presenting some of the results in their classes, e.g., the econometrics class:

This is useful for the students because they have a chance to deal with real problems and develop the kind of skills and knowledge needed to engage with policy development. Students also enjoy working on projects that may make a difference and are socially relevant. (UCT 2007, 33)

All of the above examples illustrate how social engagement has helped enrich the curriculum through utilization of socially engaged research to equip students with the knowledge and skills needed to practice as professionals in the South African context (Odora-Hoppers 2006).

\section{Challenging dominant epistemologies, and practising models of knowledge generation that build on local knowledge, and on university-community collaborations}

Several of the portraits in the social responsiveness reports illustrate how new knowledge is being generated through working in solidarity with external constituencies and learning from them thus challenging the hegemonic knowledge base of the academy (Thompson 2000). This is linked to Gibbons et al's (1994) notion of knowledge produced in 'contexts of application' as well as his notion of the 'agora' or 'transactional space' (Gibbons 2006). It also links with Swartz (2006) and his point that in relationships with external constituencies, the university must learn not to 'speak from above' but rather engage as more equal partners in more 'democratic social relations'.

The postgraduate programme in disability studies in the faculty of health sciences shows how the research community of disabled and non-disabled academics, activists, policy-makers and practitioners, coalesce in an 'agora' using participatory and action-oriented research to generate the knowledge base of a curriculum for postgraduate programmes at the university. Key principles guiding the design of the course included finding an African voice for disability driven by needs identified by the disability rights movement. This approach recognizes that the university does not necessarily know best what to include in a curriculum, and that input from stakeholders is critical to the success of the programme. It is also based on the premise that transformation cannot successfully occur through decision-making by those with power, and that genuine transformation involves shared decision-making through the establishment of 'transactional spaces' (Gibbons 2006). This in turn can generate pedagogical approaches that aim to achieve more 'democratic communities' through relationships that work to promote social justice (Hironimus-Wendt and Lovell-Troy 1999).

The portrait of the African religious health assets programme (ARHAP) describes the use of transactional spaces involving multiple stakeholders to generate knowledge about factors 
impacting on the treatment of HIV/AIDS. The background to this initiative was the contestations on the ground in South Africa about the distribution of anti-retrovirals (ARVs) which suggested that it is not enough to simply provide ARVs. Various etymologies or explanations of disease appeared to be at work and differing constructs of bodies, health and illness are involved, many of them imbued with religious images, symbols and understandings of the world. So in working in a grounded way with communities ARHAP tried to generate 'theories (which were) shaped as much by the way people actually think and work and live on the ground, as they are by prior learning' (UCT 2006, II).

ARHAP's approach is located in the body of work known as asset based community development, or capability-focused approaches, which recognizes the need to take seriously the assets that people on the ground have and build on these, rather than working from a deficit model, which is the usual approach of traditional research. As Cochrane says:

\begin{abstract}
It is the collaboration between researchers, practitioners and local communities that generates the necessary set of new and different perspectives to create new knowledge. Academics are necessarily involved in discourses that are quite technical as a result of being influenced by particular theoretical backgrounds. But on the ground it is necessary to relate the discourse and the way it is constructed to the discourses that people use on the ground. As result there may be a need for trans-cultural interpretation. (UCT 2006, II)
\end{abstract}

The new knowledge generated in these ways forms the basis of a course on religion and public health in Africa taught by the religious studies department.

Oldfield of the department of environmental and geographical studies in the faculty of science believes that SR activities challenge the boundary of what constitutes the discipline by involving a wider range of stakeholders and structuring the teaching experience as one that takes place in both the classroom on campus as well as the community. Her third year human geography course illustrates how 'socially robust' knowledge is generated through engagement with local communities in the community and national or regional development initiatives. Her course is the field-based research component of urban geography where students work together with community-based organizations in generating data on housing for ongoing lobbying work with the City of Cape Town. Through this engagement, students gain mapping skills as part of their qualification as human geographers. However the students gain far more from the projects, in particular about new and different kinds of knowledge and this is brought into the curriculum. In this way, she believes the community serves the students and shows them that the university is not the only producer of knowledge:

Communities have all sorts of knowledge and that knowledge is all over the place... knowledge is not [just] something that's found up here [at UCT]... this is a very important value. So [while] it's [about] the experience of the students and the skills of the students, it's [also about] knowledge of situations in all sorts of places and which is articulated in lots of different ways. (UCT 2005, 32)

All the examples in the section above show how engagement with outside constituencies can work to not only build an appreciation for local knowledge, but that it can also enhance more academic, university-based forms of knowledge. Through this, the curriculum can begin to challenge hegemonic forms of knowledge thereby facilitating new forms of learning and understanding for students.

\title{
Mediating the interface between theory and practice
}

A number of the portraits involve students in learning opportunities while performing a service for a community constituency. These service learning programmes incorporate experiential learning and are an explicit attempt to link theory and practice and to engage students in real 
world activities while doing their studies, supporting the philosophy of Dewey and others above (Waterman 1997; Giles and Eyler 1994).

We have already looked at the urban geography course in environmental and geographical sciences. Via reflection activities linked to core geographical concepts in the curriculum, students are provided with opportunities to question a range of assumptions about knowledge and knowledge production.

The UCT law clinic and the school of architecture have developed similar opportunities for such learning and service experiences. In the case of the school of architecture, the school responds to requests that they receive from various communities for assistance on particular projects. Once the task is assigned, the students work with the community over a period of about four months to discuss needs and to develop the design solution. Over the past six years, the school's students have completed 42 such projects of which at least 24 have been directly with historically disadvantaged communities. These include proposals for a TB and HIV clinic, an environmental resource centre, the Homestead Homeless People's Organisation and the Cape Mental Health Society. Le Grange strongly believes in this kind of teaching and learning from both a pedagogic as well as from an ethical position:

I think this project, this particular way of teaching and the simulated office studio, can only exist if it is serving the community. Ethically I don't think I would want the school to serve major property or estate agents or other private companies. (UCT 2006, 16)

The UCT law clinic operates as a fully functioning law practice with a professional staff of seven. It has two sections: a litigation practice where students can gain first hand experience of dealing with clients and legal procedures, and a refugee office which provides students the opportunity to assist asylum seekers with legal problems. As such, the clinic provides an example of a community-based education project that combines the provision of service to the community and experiential learning for the students. As one of the aims is to promote a better understanding of how different social contexts impact on the nature of legal problems experienced by the community, the project contributes to promoting citizenship and social responsibility in students. In this way, it also contributes to the training of more aware and responsive professionals.

The examples illustrate how the students' engagement with external constituencies is potentially a critical vehicle for producing academic citizens. However, critical reflection on what students learn from community engagement needs to be formally part of the curriculum and facilitated more explicitly (Van Belle, department of information systems [IS]). In the words of an IS student:

... it is important for (students) to learn that development should be socially responsive and reflective process that, when properly instituted, should benefit all parties, and is never divorced from social context. (UCT 2007, 86)

To maximize students' learning about citizenship, the department now asks students to include in their reports a short reflection on how their attitudes have changed as a result of their engagement.

\section{Transforming the curriculum to reflect changing notions of professional practice}

The final theme is that of reflecting new notions of professional practice whereby graduates enter the professions in a context like South Africa with knowledge that is generated in contexts of application. Not only is this knowledge relevant but it is also a robust response to complex and shifting professional challenges (Gibbons et al. 1994; Cox 2006)

The portrait of the child guidance clinic describes how the training of clinical psychologists has historically been geared towards equipping students to work in private practice. This 
determined the way the curriculum was structured, particularly the skills developed and the range of problems students were exposed to during the students' clinical training.

The clinic is seeking to change the content of the curriculum to produce professionals more suited to the South African context who will want to work in the community. This requires a stronger focus on the development of skills needed to work in community contexts. A crucial focus of the changed curriculum review is on teaching the students how to use theories in more versatile ways. Examples include working with the parents of trauma victims, where groups may change every week and where it is necessary to have an immediate impact; students work in the burns unit at Red Cross Children's Hospital where they co-facilitate support groups with parents of burn survivors or they facilitate support groups for the house mothers who look after the children at the SOS children's village. The formal curriculum now includes a course on community psychology, which has a strong emphasis on working in the South African context.

Another example of how social engagement can help change professional practices through contributing to changes in the curriculum involves the health and human rights project which started in 1995 in the faculty of health sciences. Since 1998 this project has run a 'train the trainer' course for staff who teach health professionals at higher education institutions in South Africa. To date, approximately 200 people have been trained. The programme provides them with the skills to implement curriculum change in their own institutions, skills related to teaching about human rights, and skills for promoting transformation. Trainees have included nurses, physiotherapists, doctors, community activists, NGO workers and lawyers, all involved in some way in the training of health professionals.

The content of these programmes has been based on the findings of research projects which the department of public health and family medicine has initiated on human rights issues affecting vulnerable groups. Initial research on the Patients Rights Charter, developed by the government, showed that human rights will not be real until people become agents of their own rights. On the basis of the lessons from this research, several staff members in the department joined the people's health movement as activists. The knowledge gained from their research on the movement's methods, using ethonographic methods, has informed the design of the health educators' curriculum.

In the disability studies programmes students are trained to work with disability as a human rights issue. As this requires skills to change mindsets in the wider society about disability the curriculum provides opportunities for students to acquire knowledge and skills related to advocacy. This in turn has impacted on the nature of the assessment tasks given to students. As a result some exams comprise half written and half oral submissions, thereby ensuring that students are assessed on oral advocacy skills. The pedagogical methods have also been adapted to ensure inclusion and recognition of alternative forms of learning - especially orality - a skill needed in advocacy and lobbying for disability issues in policy development. In these ways, the MPhil programme has thus been instrumental in extending some entrenched academic and professional practices.

This section illustrates how social engagement has resulted in critical reflection on the importance of producing graduates who are able to operate with sensitivity to the diverse needs of our people and society (Odora-Hoppers 2006).

\section{Conclusion}

In this paper, we have discussed and analysed examples of social responsiveness UCT. In particular, we have chosen those that relate to issues of curriculum transformation, of knowledge generation, and of the development of new kinds of professionals and forms of professional knowledge. We have shown how different kinds of knowledge can be accorded value in higher education curricula and how these new kinds of knowledge can contribute towards the 
development of new and responsive kinds of curricula. These issues have implications for forms of pedagogy as we have seen in the case of both the disability studies programme and the EGS field-based research courses.

The EGS case study above illustrates clearly the value of linking theory and practice and engaging in the real world as learning experiences such as these have value in assisting in students becoming more effective, responsive and committed graduates and professionals. We have seen also, through the work of a project like AHRAP, the importance of challenging dominant forms of knowledge and linking with knowledge producers outside of the academy. In other words, we have shown how engaging with society not only serves to enhance the core functions of both teaching and research, but that it can actually act to changes the knowledge base of the academy itself. Linked to this, one of the key challenges that remains in doing work of this nature is how we think about assessment practices as it is through such practices that the real bases of power in higher education are made visible.

Our final point is this. As higher education institutions, we need to ensure that we draw on the different sources of knowledge as discussed above in order to constantly refine our practice and the practice of others we engage with through our social responsiveness work. Doing this helps to strengthen our practice and construct new kinds of knowledge. Holloway from the DiMP project supports this approach. She argues that in contexts such as South Africa, closer synergy between research and practice creates a range of important opportunities and muchneeded legitimacy for actors in the field, particularly in vulnerable areas like countries in the South, to expand their production of 'locally meaningful and appropriate disaster risk research and adaptive practice'. Following Oldfield (2007) therefore, we need to understand and nourish what she calls the nexus where research, teaching and social responsiveness ${ }^{3}$ overlap because:

$\ldots$ it is a theoretical strength that adds depth, reflexivity, and, in the relationships built, the construction of robust urban knowledge. In our developing, unequal, fragmented context where policy, practice, politics and knowledge intermesh in complex ways, our challenge is to theorize 'back' to the centre (Murphy 2006) from this rich and complex base. (Oldfield 2007, 24)

\section{Notes}

I. See Naude (2006) for a discussion on the different emphases of these forms of experiential education.

2. See UCT website for a full list and description of the portraits: http://www.uctsocialresponsiveness.org.za.

3. In her paper, Oldfield uses the term 'activism' to signal the social project and orientation underpinning her teaching and research work.

\section{Notes on contributors}

Judith Favish is Director: Institutional Planning at the University of Cape Town. She holds a postgraduate diploma in higher education studies and a masters in adult and continuing education. Since 2005 she has been a member of the Higher Education Quality Committee in South Africa. She chairs the management committee of a consortium of student development agencies at the university.

Janice McMillan is Senior Lecturer in the Centre for Higher Education Development at the University of Cape Town. She holds an MPhil in education and a PhD in sociology, focused on theorizing service learning and the university-community boundary. She teaches in both adult education and service learning and works with departments at UCT on developing service learning courses.

\section{References}

Bawa, A. 2003. Rethinking community-based learning in the context of globalization. In Service enquiry I, ed. H. Perold, S. Stroud, and M. Sherraden, 47-59. Emmerentia: Global Service Institute.

Boyer, E. 1996 The scholarship of engagement. Journal of Public Service and Outreach 9, no. I: I I-20. 
Castells, M. 200I. The new global economy. In Challenges of globalisation: South African debates with Manuel Castells, ed. J. Muller, N. Cloete, and S. Badat. Cape Town: Maskew Miller Longman.

Cox, D. 2006. The how and why of the scholarship of engagement. In Creating a new kind of university: Institutionalising community-university engagement, ed. S. Percy, N. Zimpher, and M. Brukardt. Bolton, MA: Anker Publishing Company.

Dewey, J. 1916. Democracy and education. New York: The Free Press.

Dewey, J. 1927. The public and its problems. Chicago: Swallow Press.

Dewey, J. 1938. Experience and education. New York: The Macmillan Company.

Favish, J. 2005. Developing a framework for monitoring and enhancing higher education's contribution to social and economic development as part of a quality assurance system. In The decade ahead: Challenges for quality assurance in South African Higher Education, ed. M. Smout. Pretoria: SAUVCA.

Favish, J. 2006. Portraits of practice: Social responsiveness in teaching and research at the University of Cape Town. Paper presented at FOTIM Conference, June 10, Pretoria, South Africa.

Gibbons, M. 2006. Engagement as a core value in a mode 2 society. Paper presented at the CHESPHEQC/JET-CHESP Conference on Community Engagement in Higher Education, September 3-5, Cape Town, South Africa.

Gibbons, M, C. Limoges, H. Nowotny, S. Schartzman, P. Scott, and M. Trow. 1994. The new production of knowledge. London: Sage

Giles, D., and J. Eyler. 1994. The theoretical roots of service learning in John Dewey: Toward a theory of service-learning. Michigan Journal of Community Service Learning I, no. I: 77-85.

Hironimus-Wendt, R.J., and L. Lovell-Troy. 1999. Grounding service learning in social theory. Teaching Sociology 27, no. 4: 360-72.

International Consortium for Higher Education. 2000. Civic responsibility and democracy. file:// iche.sas.upenn.edu/reports/European\%Report\%20Executive\%20.summary.pdf.

Lisman, D.C. 1998. Toward a civil society: Civic literacy and service learning. Connecticut: Bergin and Garvey.

McMillan, J. 2008. What happens when the university meets the community? An analysis of service learning as 'boundary work' in higher education. PhD dissertation, Department of Sociology, Graduate School of Humanities, University of Cape Town.

Ministry of Education. 200I. National plan for higher education. Pretoria: Department of Education.

Moore, D. 2000. The relationship between experiential learning research and service-learning research. Michigan Journal of Community Service-Learning Special Issue: 124-8.

Murphy, B.M. 2000. Universities as sites of democracy and civic responsibility. file://iche.sas.upenn.edu/ reports/sanfrancisco.pdf.

Naude, L. 2006. Community engagement through teaching and learning. Paper presented at the CHESPHEQC/JET-CHESP Conference on Community Engagement in Higher Education, September 3-5, Cape Town, South Africa.

Nyden, P. 2006. The challenges and opportunities of engaged research. Paper presented at the CHESPHEQC/JET-CHESP Conference on Community Engagement in Higher Education, September 3-5, Cape Town, South Africa.

Odora-Hoppers, C. 2006. Constructing a conceptual framework for HBUs in a developmental paradigm. In Within the realm of possibility: From disadvantage to development at the University of Fort Hare and the University of the North, ed. M. Nkomo, D. Swartz, and B. Maja. Cape Town: Human Sciences Research Council Press.

Oldfield, S. 2007. Making sense of multiple conversations: research, teaching and activism in and with 'communities' in South Africa cities. South African Geographical Journal December: 104-10.

Stanton, T. 2000. Bringing reciprocity to service-learning research and practice. Michigan Journal of Community Service-Learning Special Issue: II9-23.

Swartz, D. 2006. New pathways to sustainability: African universities in a globalising world. In Within the realm of possibility: From disadvantage to development at the University of Fort Hare and the University of the North, ed. M. Nkomo, D. Swartz, and B. Maja. Cape Town: Human Sciences Research Council Press.

University of Cape Town. 2005. Social responsiveness report. Portraits of practice: Social responsiveness in teaching and research. Cape Town: University of Cape Town.

University of Cape Town. 2006. Social responsiveness report: Portraits of practice. Cape Town: University of Cape Town.

University of Cape Town. 2007. Social responsiveness report: Portraits of practice. Cape Town: University of Cape Town.

Waterman, A.S. 1997. Service-learning: Applications from the research. Mahwah, NJ: Lawrence Erlbaum Associates. 